\title{
Correction to: Deletion of the hypothetical protein SCO2127 of Streptomyces coelicolor allowed identification of a new regulator of actinorhodin production
}

Víctor H. Tierrafría ${ }^{1}$. Cuauhtemoc Licona-Cassani ${ }^{2}$ - Nidia Maldonado-Carmona ${ }^{1}$ - Alba Romero-Rodríguez ${ }^{1}$. Sara Centeno-Leija ${ }^{1,3} \cdot$ Esteban Marcellin ${ }^{2} \cdot$ Romina Rodríguez-Sanoja ${ }^{1} \cdot$ Beatriz Ruiz-Villafán ${ }^{1} \cdot$ Lars K. Nielsen $^{2}$. Sergio Sánchez ${ }^{1}$

Published online: 9 March 2020

(C) Springer-Verlag GmbH Germany, part of Springer Nature 2020

Correction to: Appl Microbiol Biotechnol (2016) 100:9229-9237

https://doi.org/10.1007/s00253-016-7811-2

The published online version of this paper contains mistake. The authors first and last names have been interchanged. The correct version is given above.

Publisher's note Springer Nature remains neutral with regard to jurisdictional claims in published maps and institutional affiliations.

The online version of the original article can be found at https://doi.org/ 10.1007/s00253-016-7811-2

Sergio Sánchez

sersan@biomedicas.unam.mx

1 Instituto de Investigaciones Biomédicas, Universidad Nacional Autónoma de México (UNAM), 04510 Ciudad de México, Mexico

2 Australian Institute for Bioengineering and Nanotechnology, The University of Queensland, QLD St. Lucia 4072, Australia

3 Laboratorio de Bioingeniería, Universidad de Colima, Coquimatlán, 28400 Colima, Mexico 